\title{
Rac1-mediated signaling plays a central role in secretion-dependent platelet aggregation in human blood stimulated by atherosclerotic plaque
}

\author{
Suman Dwivedi', Dharmendra Pandey ${ }^{1,3}$, Anna L Khandoga ${ }^{1}$, Richard Brandl ${ }^{2}$, Wolfgang Siess ${ }^{1 *}$
}

\begin{abstract}
Background: Platelet activation requires rapid remodeling of the actin cytoskeleton which is regulated by small GTP-binding proteins. By using the Rac1-specific inhibitor NSC23766, we have recently found that Rac1 is a central component of a signaling pathway that regulates dephosphorylation and activation of the actin-dynamising protein cofilin, dense and $\alpha$-granule secretion, and subsequent aggregation of thrombin-stimulated washed platelets.

Objectives: To study whether NSC23766 inhibits stimulus-induced platelet secretion and aggregation in blood.

Methods: Human platelet aggregation and ATP-secretion were measured in hirudin-anticoagulated blood and platelet-rich plasma (PRP) by using multiple electrode aggregometry and the Lumi-aggregometer. Platelet P-selectin expression was quantified by flow cytometry.

Results: NSC23766 (300 $\mu \mathrm{M})$ inhibited TRAP-, collagen-, atherosclerotic plaque-, and ADP-induced platelet aggregation in blood by $95.1 \%, 93.4 \%, 92.6 \%$, and $70 \%$, respectively. The $I C_{50}$ values for inhibition of TRAP-, collagen-, and atherosclerotic plaque-, were $50 \pm 18 \mu \mathrm{M}, 64 \pm 35 \mu \mathrm{M}$, and $50 \pm 30 \mu \mathrm{M}$ NSC23766 (mean \pm SD, $n=3-7$ ), respectively. In blood containing RGDS to block integrin $\alpha_{\| b} \beta_{3}$-mediated platelet aggregation, NSC23766 $(300 \mu \mathrm{M})$ completely inhibited P-selectin expression and reduced ATP-secretion after TRAP and collagen stimulation by $73 \%$ and $85 \%$, respectively. In ADP-stimulated PRP, NSC23766 almost completely inhibited P-selectin expression, in contrast to aspirin, which was ineffective. Moreover, NSC23766 (300 $\mu \mathrm{M})$ decreased plaque-stimulated platelet adhesion/aggregate formation under arterial flow conditions $\left(1500 \mathrm{~s}^{-1}\right)$ by $72 \%$.

Conclusions: Rac1-mediated signaling plays a central role in secretion-dependent platelet aggregation in blood stimulated by a wide array of platelet agonists including atherosclerotic plaque. By specifically inhibiting platelet secretion, the pharmacological targeting of Rac1 could be an interesting approach in the development of future antiplatelet drugs.
\end{abstract}

\section{Background}

After rupture of atherosclerotic plaques thrombogenic matrix components and lipids are locally exposed to circulating platelets [1-5]. By adhering to these sites, platelets rapidly become activated, leading to secretion of their granule contents such as ADP that recruits circulating platelets into large aggregates culminating in the formation of platelet thrombi $[5,6]$. The latter are

\footnotetext{
* Correspondence: wsiess@med.uni-muenchen.de

${ }^{1}$ Institute for Prevention of Cardiovascular Diseases, University of Munich, Munich, Germany

Full list of author information is available at the end of the article
}

potentially life-threatening by occluding coronary and cerebral arteries.

The step-wise activation of platelets (adhesion, shape change, secretion and aggregation) involves an organized remodeling of the actin cytoskeleton. The major molecules involved in actin dynamics are the small GTP-binding proteins Rho, Rac, and Cdc42. These proteins differentially regulate the reorganization of the actin cytoskeleton, leading to the formation of different cellular structures. In platelets, Rho activation mainly regulates the $\mathrm{Ca}^{2+}$ independent cell spheration and contractility during shape change through stimulation of the Rho-kinase ROCK,
C Biomed Central

C 2010 Dwivedi et al; licensee BioMed Central Ltd. This is an Open Access article distributed under the terms of the Creative Commons Attribution License (http://creativecommons.org/licenses/by/2.0), which permits unrestricted use, distribution, and reproduction in any medium, provided the original work is properly cited. 
whereas Rac1 has been reported to be essential for the formation of lamellipodia during platelet spreading [7-9]. Rac1 activation in platelets is $\mathrm{Ca}^{2+}$-dependent $[10,11]$, and it has been shown to be involved in regulating secretion and subsequent aggregation in human platelets stimulated with thrombin $[12,13]$. However, in mice platelets, the results regarding the role of Rac1 in thrombin-induced aggregation and secretion are controversial $[9,12,14]$. By using conditional Rac1 knock-out mice, only one study showed impaired thrombin-induced aggregation [12]. In the two other studies, thrombin-induced secretion and aggregation were not affected; Rac1 was found to be involved only in collagen/glycoprotein VI-mediated platelet activation $[9,14]$.

An important tool in studying the function of Rac1 is the compound NSC23766, a small-molecule inhibitor that fits into a surface groove of Rac1 known to be critical for the binding of specific guanine nucleotide exchange factors (GEFs) converting Rac-GDP into its active Rac-GTP form. NSC23766 inhibits in vitro Rac1 binding and activation by the Rac-specific GEF Trio or Tiam1 [15]. The specific Rac-inhibitor NSC23766 has been used in more than 90 scientific studies in which the results obtained have often been validated by Racsilencing and Rac knock-out experiments (see http:// www.ncbi.nlm.nih.gov/pubmed).

By using NSC23766, our group recently unraveled a $\mathrm{Ca}^{2+}$-dependent pathway regulating secretion in thrombin-stimulated human platelets linking Rac1 activation to actin dynamics: Calcineurin $\rightarrow$ Rac1 $\rightarrow$ class-II PAKs activation $\rightarrow$ cofilin dephosphorylation and activation [13]. In the present study, we asked whether NSC23766 could inhibit human platelet secretion and aggregation induced by other platelet stimuli, particularly atherosclerotic plaque, and also whether it could reduce platelet function under more physiological conditions such as in blood. We report here that NSC23766 indeed blocks secretion and secretion-dependent aggregation in PRP and blood induced by ADP, TRAP, collagen and human atherosclerotic plaque, and notably plaque-stimulated platelet thrombi formation under arterial flow conditions. Such a broad inhibitory profile of a Rac1 inhibitor suggests that pharmacological targeting of Rac1 is an interesting approach for developing future antiplatelet drugs.

\section{Methods \\ Materials}

Acetylsalicylic acid was obtained from Fluka Chemie. Adenosine 3'-phosphate 5'-phosphate (ADP) was from Biopool (Wicklow, Ireland). Arg-Gly-Asp-Ser (RGDS) peptide was from Bachem Biochemica (Heidelberg, Germany). Albumin (fatty acid free) was purchased from Sigma. Collagen (Horm) was obtained from Nycomed
Pharma (Unterschleißeim, Germany). Luciferase luciferin reagent was obtained from Chrono-Log corp (Havertown, PA). Microfluidic chambers were from Bioflux (Fluxion, San Francisco, California, USA). NSC23766 was obtained from Tocris Bioscience (Bristol, UK). Red blood cell (RBC) lysing buffer was from AbD Serotec (Oxford, UK).Formaldehyde was obtained from Sigma (Taufkirchen, Germany). Recombinant lepirudin was obtained from Pharmion (Refludan', Germany). TRAP-6 (SFLLRN-OH, thrombin activating peptide) was from Bachem Biochemica (Heidelberg, Germany). The following monoclonal antibodies directly conjugated to fluorochromes were purchased from BD Biosciences (Heidelberg, Germany): phycoerythrin-(PE) conjugated anti-CD41a (HIP8) and fluorescein isothiocyanate(FITC) conjugated anti CD62P (AK-4).

\section{Isolation of human atheromatous plaques}

Atherosclerotic tissue specimens were collected from patients who underwent surgery for high grade carotid artery stenosis as described previously [16]. Patient consent was obtained and approved by the Ethics Committee of the Faculty of Medicine of the University of Munich. Plaque specimens were immediately frozen at $-80^{\circ} \mathrm{C}$ after surgical removal. The atheromatous plaques, macroscopically visible by their yellowish color, were dissected under sterile conditions from other regions of atherosclerotic tissue. Calcified plaques were discarded. The plaques were characterized by histological analysis as atheroma with a thin fibrous capsule. Plaques were homogenized and processed as described $[5,17]$. The plaque concentration was adjusted to $100 \mathrm{mg} / \mathrm{ml}$. Plaque homogenates from individual patients were pooled and used for the experiments.

\section{Preparation of blood}

After informed consent was given, blood was collected from healthy volunteers using a 19-gauge needle and plastic syringe containing hirudin $(\sim 200 \mathrm{U} / \mathrm{ml}$ in blood). In some of the experiments, acetylsalicylic acid (ASA) was added to the anticoagulant [17]. The final concentration of ASA in the blood was $1 \mathrm{mM}$.

\section{Platelet aggregation and ATP-secretion in blood}

Whole blood platelet aggregation was determined by impedance aggregometry as described previously [18]. In brief, a $1: 1$ mixture of $0.9 \% \mathrm{NaCl}$ and whole blood was incubated for $5 \mathrm{~min}$ at $37^{\circ} \mathrm{C}$ whilst stirring in the presence or absence of different concentrations of NSC23766 and was then stimulated with collagen $(0.5 \mu \mathrm{g} / \mathrm{ml})$, atherosclerotic plaque homogenate $(0.42 \mathrm{mg} / \mathrm{ml})$, TRAP $(5 \mu \mathrm{M})$ and ADP $(5 \mu \mathrm{M})$. The increase in electrical impedance was recorded for $5 \mathrm{~min}$, and the mean value of the area under the curve of two independent recordings (AU*min) 
was taken. For some experiments, blood with aspirin $(1 \mathrm{mM})$ was taken and stimulated with ADP $(5 \mu \mathrm{M})$ in the presence and absence of NSC23766 $(300 \mu \mathrm{M})$.

For measuring ATP-secretion, a 1:1 mixture of 0.9\% $\mathrm{NaCl}$ and whole blood was taken. The samples were preincubated with NSC23766 $(300 \mu \mathrm{M})$ or solvent (water) for $5 \mathrm{~min}$ at $37^{\circ} \mathrm{C}$ whilst stirring $(1000 \mathrm{rpm})$ in the aggregometer cuvettes. Luciferase-luciferin reagent $(50 \mu \mathrm{l}$ of $17.6 \mathrm{U} / \mathrm{ml}$ ) was added for each reaction of $400 \mu \mathrm{l}$ blood-saline mixture, and the increase of luminescence after exposure of stirred blood to platelet stimuli was recorded in the lumi-aggregometer (Chronolog, Havertown, PA)[19]. To some of the samples, RGDS (2 $\mathrm{mM}$ ) or solvent (water) was added.

\section{Platelet aggregation and ATP-secretion in platelet rich plasma}

Platelet-rich plasma (PRP) was prepared from hirudinanticoagulated blood by centrifuging the blood at $160 \times \mathrm{g}$ for $20 \mathrm{~min}$ at room temperature (RT). Luciferin-luciferase was added, and aggregation of PRP and simultaneous ATP-secretion were determined at $37^{\circ} \mathrm{C}$ whilst stirring $(1000 \mathrm{rpm})$ in the lumi-aggregometer. PRP whilst stirring was pre-incubated with different concentrations of $\mathrm{NSC} 23766$ or solvent (water) for $5 \mathrm{~min}$ at $37^{\circ} \mathrm{C}$. In some of the samples, RGDS ( $1 \mathrm{mM}$ ) or solvent (water) was added 2 min before stimulation of PRP with ADP $(5 \mu \mathrm{M})$, collagen $(1.25 \mu \mathrm{g} / \mathrm{ml})$, or atherosclerotic plaque homogenate $(0.625 \mathrm{mg} / \mathrm{ml})$. In some of the experiments, acetylsalicylic acid (1 M in ethanol) was added to the PRP (final concentration $1 \mathrm{mM}$ ) and incubated for $30 \mathrm{~min}$. PRP was exposed to ADP $(5 \mu \mathrm{M})$ in the presence or absence of NSC23766 $(300 \mu \mathrm{M})$.

\section{P-selectin expression in PRP and blood}

All experiments were performed in the presence of RGDS (1 mM). PRP (with and without aspirin pretreatment), stirred in the LABOR-aggregometer (Hamburg, Germany), was incubated with NSC23766 $(300 \mu \mathrm{M})$ or solvent (water) for $5 \mathrm{~min}$ at $37^{\circ} \mathrm{C}$ before stimulation with collagen $(5 \mu \mathrm{g} / \mathrm{ml})$ or ADP $(5 \mu \mathrm{M})$ for $2 \mathrm{~min}$. Samples were fixed with equal volumes of Dulbecco's phosphate buffered saline (PBS) containing 3.7\% formaldehyde for $30 \mathrm{~min}$ at room temperature. After fixation, samples were centrifuged in a microfuge for $5 \mathrm{~min}$ at $2300 \times \mathrm{g}$. Pellets were washed twice with PBS. The pellets were incubated for $15 \mathrm{~min}$ in the dark at room temperature with CD62P-FITC or IgG- FITC $(6 \mu \mathrm{l})$. P-selectin positive cells were quantified by flow cytometry (FACScan, Becton Dickinson, NJ, USA) and CELLQuest software. For each sample, a minimum of 10000 events was counted. For analysis, the percentage of positive cells was counted, and isotype matched IgG-FITC labeled platelets were subtracted from CD62P-FITC labeled platelets.
For P-selectin expression in blood, all experiments were performed in the presence of RGDS ( $2 \mathrm{mM})$. Aliquots $(600 \mu \mathrm{l})$ of blood $(0.9 \% \mathrm{NaCl}$ and blood $1: 1$ mixture) were incubated with NSC23766 $(300 \mu \mathrm{M})$ or solvent (water) for $5 \mathrm{~min}$ at $37^{\circ} \mathrm{C}$ whilst stirring in an impedance aggregometer (Multiplate ${ }^{\bullet}$ analyzer, Dynabyte Medical; Munich) before stimulation with collagen $(5 \mu \mathrm{g} / \mathrm{ml})$ or TRAP $(5 \mu \mathrm{M})$. After $2 \mathrm{~min}$, an aliquot of $100 \mu \mathrm{l}$ blood was added to $1.5 \mathrm{ml} 1 \times \mathrm{RBC}$ lysis buffer, and platelets were fixed for 1 hour at room temperature. After fixation, samples were centrifuged in a microfuge for $8 \mathrm{~min}$ at $2300 \times$ g. Pellets were washed twice with PBS. The pellets were incubated for $15 \mathrm{~min}$ in the dark at room temperature with CD41a-PE and CD62P-FITC (6 $\mu \mathrm{l}$ each). Platelets were gated by CD41a-PE fluorescence, and P-selectin positive cells were quantified by flow cytometry (FACScan, Becton Dickinson, NJ, USA) and CELLQuest software as described above.

\section{Analysis of platelet adhesion and thrombus formation in flowing whole blood}

For flow experiments, T-BIO-FLUX200 (Fluxion, San Francisco, California, USA) with high shear plates (48 wells, up to 200 dyne $/ \mathrm{cm}^{2}$ ) was used. The microfluidic chambers were coated with $20 \mu$ of plaque homogenate $(5 \mathrm{mg} / \mathrm{ml})$ dissolved in PBS containing $0.1 \%$ fatty acid-free albumin from the outlet channel. Care was taken to coat the viewing window of the channel and to leave the inlet channel free. The plaque coating was allowed to dry at room temperature overnight. Before the experiment, the channels were perfused with PBS (containing $0.3 \%$ albumin) for $10 \mathrm{~min}$ at a wall shear rate of $500 \mathrm{~s}^{-1}$. Then hirudin-anticoagulated blood containing mepacrine $(10 \mu \mathrm{M})$ in order to visualize platelets was added to the inlet well, and chambers were perfused for $10 \mathrm{~min}$ at a wall shear rate of $1500 \mathrm{~s}^{-1}$.

The plaque-coated microfluidic high shear plates were mounted on the stage of an upright microscope (Nikon TE2000E-PFS, Tokyo, Japan). Control blood and blood with NSC23766 $(300 \mu \mathrm{M})$ was prewarmed to $37^{\circ} \mathrm{C}$ for 5 min prior to the start of flow, and experiments were performed at $37^{\circ} \mathrm{C}$. Platelet deposition was observed and recorded in real-time (100 frames per sec) with a CCD camera (CooLSNAP HQ2, Tuscon AZ; USA). We used bright field and fluorescence microscopy for real-time visualization of platelet adhesion and aggregation in flowing blood. Control blood and blood containing NSC23766 were observed simultaneously in parallel channels. For each flow experiment, perfused surface fields of the size of $237900 \mu \mathrm{m}^{2}$ (located in the middle of the channels of the viewing window) were recorded, and fluorescence images were later analyzed off-stage by quantifying the area covered by platelets with the 
software NIS-element 3.0 version. In each field, the areas covered by platelets were quantified.

\section{Statistical analysis}

Results are reported as mean \pm SD from 3-7 experiments conducted with blood or PRP from different donors. Statistical significance was assessed by either paired Student's t-test or signed rank test where appropriate. Differences were considered significant when $p$ was $<0.05$.

\section{Results}

NSC23766 inhibits platelet aggregation upon stimulation of blood and PRP by TRAP, collagen and atherosclerotic plaque

Platelet aggregation in blood induced by TRAP $(5 \mu \mathrm{M})$ activating the PAR-1 receptor was reduced by $300 \mu \mathrm{M}$ NSC23766 from $644 \pm 37$ to $59 \pm 40$ AU*min (control $29 \pm 13$ AU*min; $n=3$ ) which corresponds to $95.1 \%$ inhibition (Figure 1). The $\mathrm{IC}_{50}$ of NSC23766 for inhibition of TRAP-stimulated aggregation was $50 \pm 18 \mu \mathrm{M}$.

Platelet aggregation stimulated by collagen $(0.5 \mu \mathrm{g} / \mathrm{ml})$ was reduced by $300 \mu \mathrm{M}$ NSC23766 from $542 \pm 181$ to $76 \pm 56 \mathrm{AU}^{*}$ min (control $43 \pm 25 \mathrm{AU} * \min ; n=7$ ) which amounts to $93.4 \%$ inhibition of (Figure 1). The $\mathrm{IC}_{50}$ of NSC23766 for inhibition of collagen-stimulated aggregation in blood was $64 \pm 35 \mu \mathrm{M}$.

Plaques contain collagenous structures that directly stimulate platelet adhesion and aggregation which is mediated mainly by stimulation of GPVI [5]. Platelet aggregation induced by plaque was reduced by $300 \mu \mathrm{M}$ NSC23766 from $289 \pm 89$ to $52 \pm 26$ AU*min (control $33 \pm 13 \mathrm{AU}$ *min; $n=3$ ) which corresponds to $92.6 \%$ inhibition (Figure 1). The $\mathrm{IC}_{50}$ of NSC23766 for inhibition of plaque-stimulated aggregation in blood was found to be $50 \pm 30 \mu \mathrm{M}$.

We also found that NSC23766 dose-dependently inhibited stimulus-induced aggregation of PRP (additional files 1 and 2, Figures S1 and S2). Platelet aggregation stimulated by collagen and plaque was completely inhibited by $300 \mu \mathrm{M}$ NSC23766. The $\mathrm{IC}_{50}$ of NSC23766 for inhibition of collagen and plaque-stimulated aggregation of PRP was found to be $47 \pm 14 \mu \mathrm{M}$, and $57.5 \pm$ $20 \mu \mathrm{M}$, respectively.

\section{NSC23766 inhibits platelet ATP-secretion upon} stimulation of blood and PRP by TRAP, collagen, and atherosclerotic plaque

Inhibition of stimulus-induced platelet aggregation in blood by NSC23766 might be due to inhibition of secretion as observed previously in our study of thrombinstimulated washed platelets [13]. Therefore, we studied the effect of NSC23766 on dense granule secretion by measuring the ATP-secretion in stirred blood. NSC23766
$(300 \mu \mathrm{M})$ inhibited ATP-secretion induced by $5 \mu \mathrm{M}$ TRAP (Figure 2A) and $0.5 \mu \mathrm{g} / \mathrm{ml}$ collagen (Figure $2 \mathrm{~B}$ ) by $60 \pm 31 \%(n=4)$ and $78 \pm 7 \%(n=6)$, respectively. In order to study the effect of NSC23766 on secretion independent of platelet aggregation, blood was pre-incubated with RGDS ( $2 \mathrm{mM})$ to block the integrin $\alpha_{\text {IIb }} \beta_{3}$. RGDS reduced ATP-secretion by $26 \pm 10 \%(p<0.003 ; n=4)$ in TRAP-stimulated blood and by $63 \pm 14 \%(p<0.04 ; n=$ 6 ) in collagen-stimulated blood (Figure 2A, B). Further pre-incubation with NSC23766 $(300 \mu \mathrm{M})$ inhibited ATPsecretion by $73 \pm 15 \%(p<0.03 n=4)$ and by $85 \pm 4 \%(p<$ $0.004 n=6)$ after stimulation with TRAP and collagen, respectively.

In PRP, RGDS reduced ATP-secretion by $92 \pm 3 \%$ when stimulated with collagen and by $86 \pm 7 \%$ when stimulated with plaque (additional files 1 and 2, Figure S1B, Figure S2B). Additional pre-incubation with NSC23766 $(300 \mu \mathrm{M})$ inhibited ATP-secretion by $98 \pm$ $1 \%$ in collagen-stimulated PRP (RGDS vs.RGDS + NSC23766: $p<0.03 ; n=4)$ and by $99 \pm 1 \%$ in plaquestimulated PRP $(p<0.04 n=4)$. The results in PRP support our findings in blood that NSC23766 inhibits platelet aggregation due to inhibition of secretion.

\section{NSC23766 inhibits ADP-induced aggregation of platelets in blood and PRP}

The extent of inhibition of stimulus-induced ATPsecretion in blood by NSC23766 (60-80\%) was less than that of inhibition of platelet aggregation (92-95\%). This discrepancy might be explained by an inhibitory action of NSC23766 on the platelet stimulatory effect of the remaining secreted ADP. Indeed, NSC23766 inhibited ADP-induced platelet aggregation in blood and PRP; this inhibition was $70 \%$ and $75 \%$, respectively (Figure 3A, B).

NSC23766 inhibits P-selectin expression on platelets upon stimulation of blood and PRP

To study whether NSC23766 also inhibits $\alpha$-granule secretion, we examined the platelet surface expression of P-selectin in the presence and absence of NSC23766 in stirred blood containing RGDS. We found that NSC23766 completely inhibited P-selectin expression after stimulation with TRAP $(5 \mu \mathrm{M})$ and collagen $(5 \mu \mathrm{g} / \mathrm{ml})$ (Table 1$)$. Also in PRP, NSC23766 effectively inhibited P-selectin expression induced by ADP $(5 \mu \mathrm{M})$ and collagen $(5 \mu \mathrm{g} / \mathrm{ml})$ (Table 2).

NSC23766 inhibits P-selectin expression and platelet aggregation stimulated by ADP independently of platelet cyclooxgenase activity

Aspirin reduced P-selectin expression of PRP by $89.8 \%$, when stimulated with collagen but not when stimulated with ADP (Figure 3B). NSC23766 (300 $\mu \mathrm{M})$ almost 
(A)

(B)
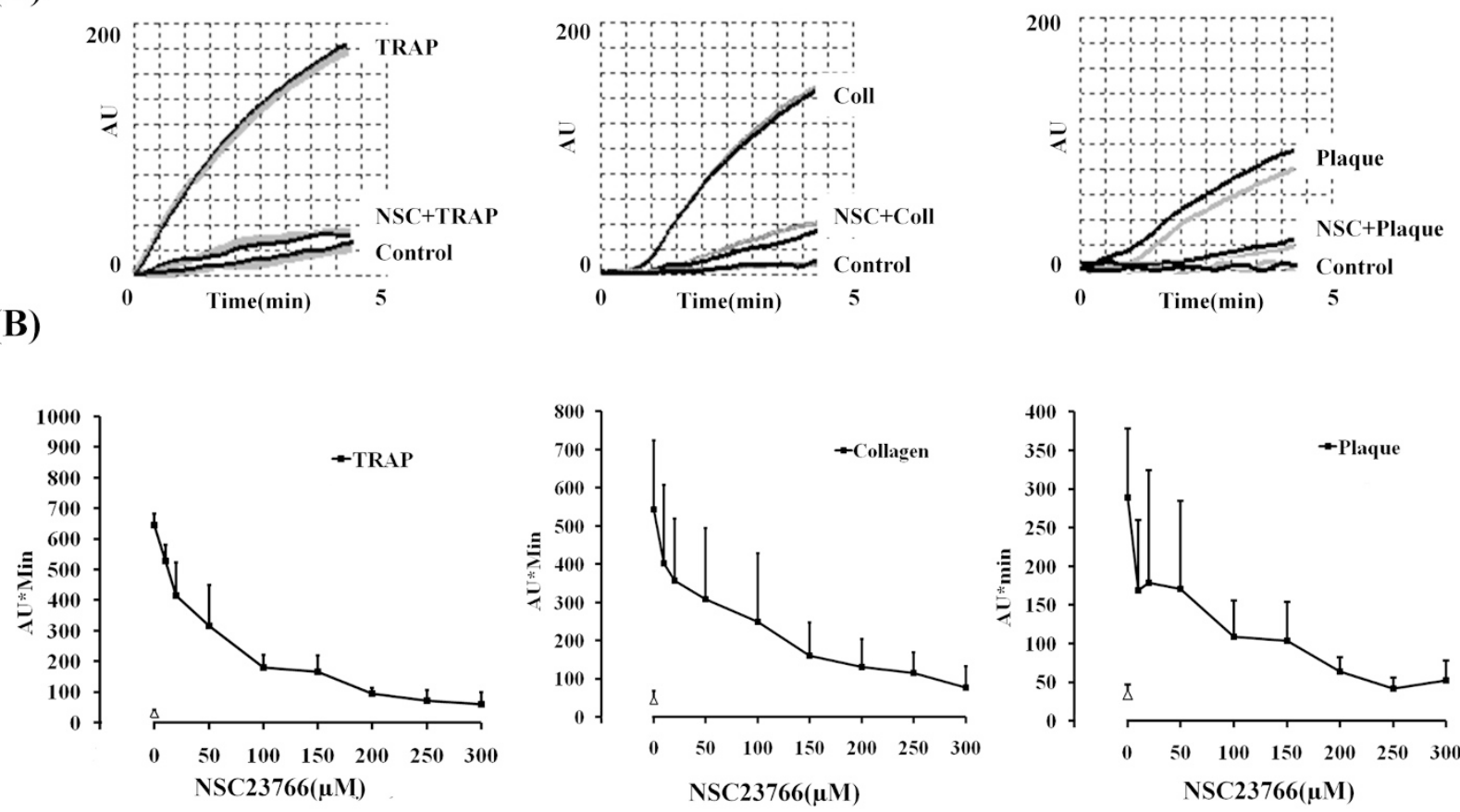

Figure 1 Effect of NSC23766 on stimulus-induced platelet aggregation in blood. (A) Hirudin-anticoagulated blood was pretreated with NSC23766 $(300 \mu \mathrm{M})$ or solvent $\left(\mathrm{H}_{2} \mathrm{O}\right)$ for 5 min whilst stirring at $37^{\circ} \mathrm{C}$ before stimulation with TRAP $(5 \mu \mathrm{M})$, collagen $(0.5 \mu \mathrm{g} / \mathrm{ml})$ or atherosclerotic plaque homogenate $(0.62 \mathrm{mg} / \mathrm{ml})$ for $5 \mathrm{~min}$; representative impedance tracings. (B) Dose-response curves of NSC23766; values are mean \pm SD $(n=4)$.

completely inhibited ADP-induced P-selectin expression in non-aspirin and aspirin-pretreated PRP (Table 2), and reduced ADP-stimulated platelet aggregation of untreated PRP and aspirin-pretreated PRP to a similar degree, by $70 \%$ and $75 \%$, respectively (Figure $3 \mathrm{~B}$ ). NSC23766 $(300 \mu \mathrm{M})$ also inhibited ADP-induced platelet aggregation in blood by $70 \%$ and $75 \%$ in the absence or presence of aspirin, respectively (Figure 3A). The results indicate that NSC23766 effectively inhibits $\alpha$-granule secretion and platelet aggregation stimulated by ADP, and that the mechanism is independent of platelet prostaglandin-endoperoxide and thromboxane formation.

\section{NSC23766 inhibits human plaque-induced platelet}

\section{thrombus formation under flow conditions}

The effects of NSC23766 on human plaque-induced platelet aggregation and thrombus formation under arterial flow conditions are shown in Figure 4. After perfusion of hirudin-anticoagulated blood over plaque-coated surfaces at $37^{\circ} \mathrm{C}$ with a wall shear rate of $1500 \mathrm{~s}^{-1}$, rapid platelet adhesion and aggregate formation were observed (additional file 3 Movie S1; Figure 4a). The platelet coverage of the plaque-coated channels $10 \mathrm{~min}$ after start of flow was $36314 \pm 30013 \mu \mathrm{m}^{2}($ mean \pm SD; $n=5)$.
NSC23766 $(300 \mu \mathrm{M})$ reduced plaque-induced platelet adhesion and aggregate formation. After NSC23766 incubation of blood, the platelet coverage was inhibited by $72 \%$ to $10322 \pm 9226 \mu \mathrm{m}^{2}$ (mean $\pm \mathrm{SD} ; n=5 ; p<$ 0.002).

\section{Discussion}

In the present study, we have provided further evidence for a central role of Rac1 in the regulation of secretion and aggregation of human platelets activated by a broad range of platelet stimuli including atherosclerotic plaque. Moreover, we have demonstrated the efficacy of NSC23766 to inhibit platelet secretion and aggregation induced by these stimuli in blood, and we have shown that NSC23766 reduces plaque-induced platelet thrombus formation under arterial flow conditions.

Blood platelets are often studied after purifying platelets from their milieu, which excludes the influence exerted by other blood cells and factors present in plasma (e.g., high concentrations of albumin and fibrinogen, lipids exposed on LDL and HDL particles) on the physiological platelet response. Sometimes, pharmacological or physiological platelet inhibitors even fail to act on platelets in blood. For example, lysophosphatidic acid-receptor antagonists effective in washed platelets 


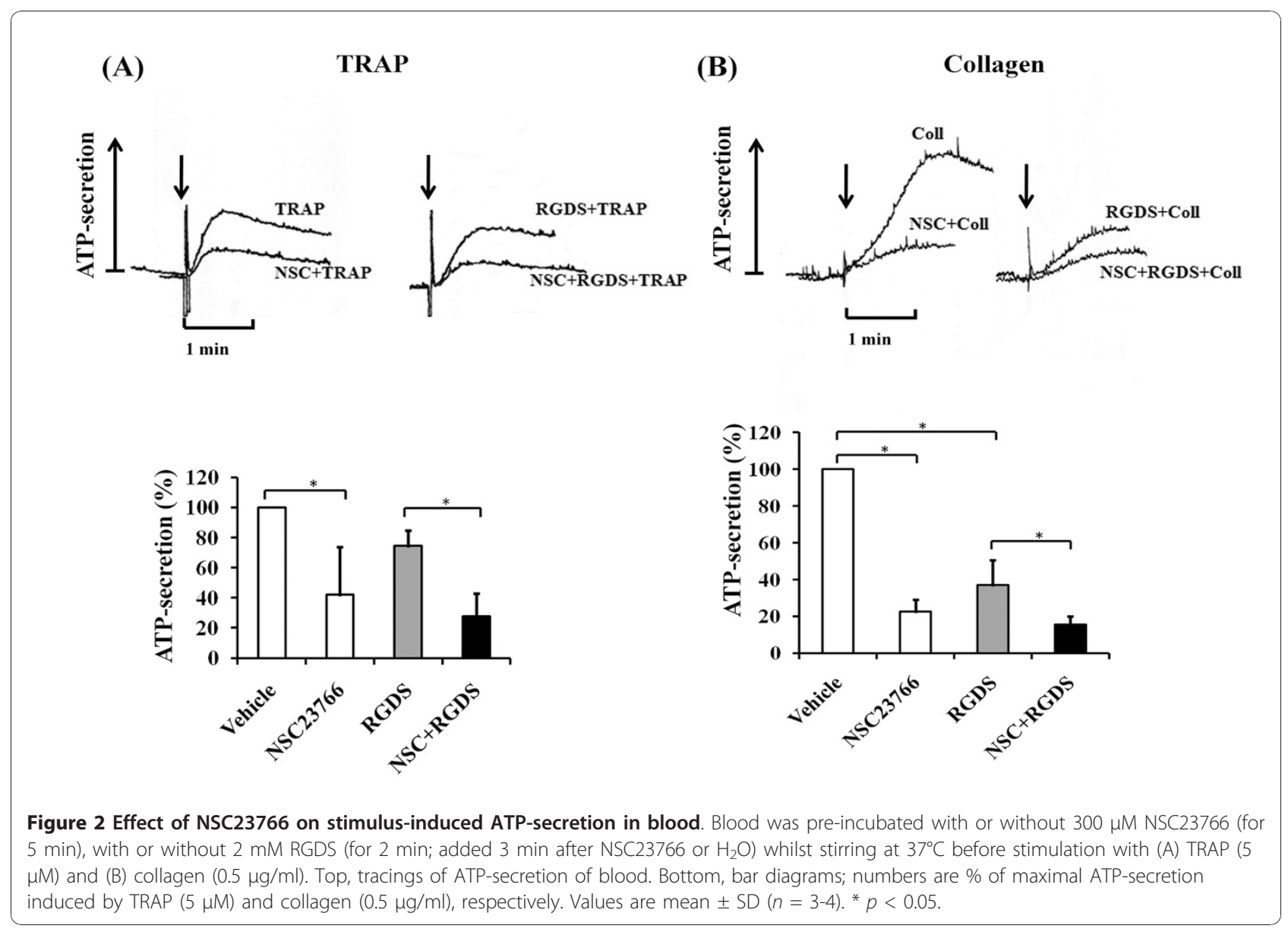

(A)

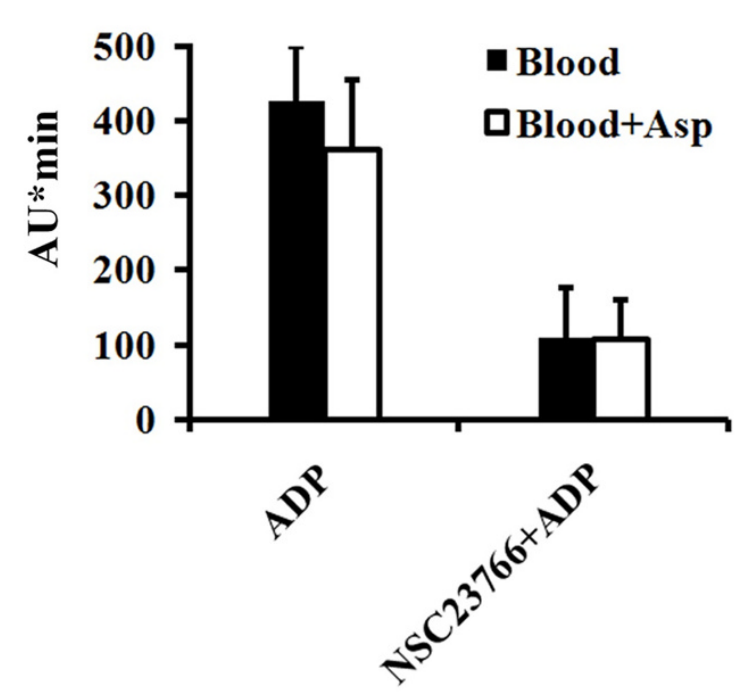

(B)

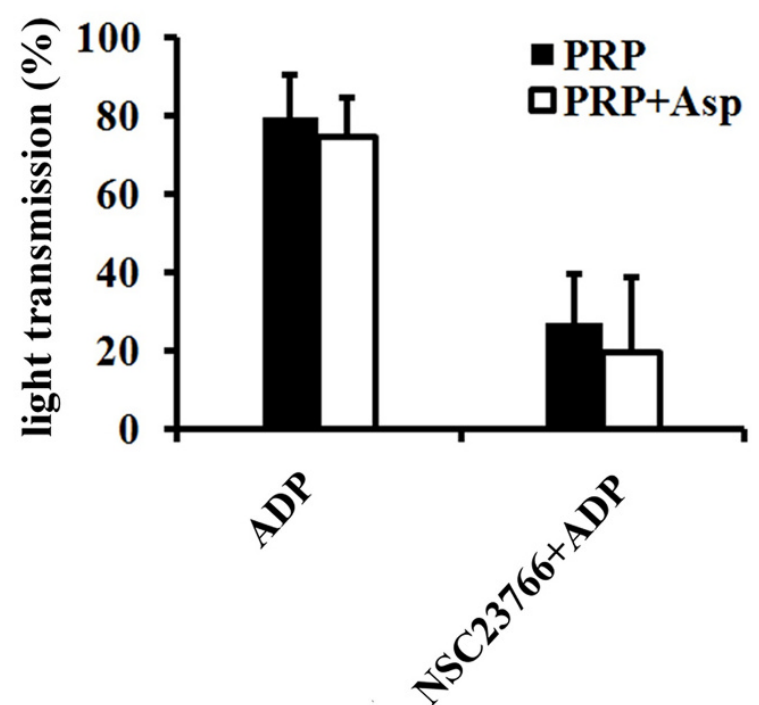

Figure 3 Effect of NSC23766 on aggregation of platelets in blood and PRP stimulated with ADP. (A) Blood (with or without aspirin) or (B) PRP (with or without aspirin) was pre-treated with $300 \mu \mathrm{M} \mathrm{NSC23766} \mathrm{for} 5 \mathrm{~min}$ whilst stirring at $37^{\circ} \mathrm{C}$ before stimulation with $\mathrm{ADP}(5 \mu \mathrm{M})$. Aggregation values of PRP are $\%$ of maximal aggregation induced by collagen $(5 \mu \mathrm{g} / \mathrm{ml})$. Values are mean \pm SD $(n=4) .{ }^{*} p<0.05$. 
Table 1 Effect of NSC23766 on P-selectin expression of platelets in blood stimulated by TRAP and collagen

\begin{tabular}{lcc}
\hline Agonist & \multicolumn{2}{c}{$\begin{array}{c}\text { P-selectin expression (\% positive } \\
\text { cells) }\end{array}$} \\
\hline & Control & Stimulated \\
\cline { 2 - 3 } TRAP $(5 \mu \mathrm{M})$ & $1.6 \pm 0.6$ & $6.8 \pm 3.4$ \\
TRAP+NSC23766 $(300 \mu \mathrm{M})$ & & $1.4 \pm 0.6$ \\
Collagen $(5 \mu \mathrm{g} / \mathrm{ml})$ & $1.7 \pm 0.9$ & $8 \pm 2.6$ \\
Collagen+NSC23766 $(300 \mu \mathrm{M})$ & & $2.9 \pm 2$ \\
\hline
\end{tabular}

Blood was incubated with NSC23766 $(300 \mu \mathrm{M})$ or solvent (water) in the presence of $2 \mathrm{mM}$ RGDS for $5 \mathrm{~min}$ whilst stirring at $37^{\circ} \mathrm{C}$ before stimulation with TRAP or collagen. P-selectin expression was measured by flow cytometry. Values are mean $\pm S D, n=3$.

do not inhibit lysophosphatidic acid stimulation of platelets in PRP and blood (Rother E, Khandoga AL, Siess W, unpublished data), and $\mathrm{PGI}_{2}$, in contrast to washed platelets and PRP, was reported to be unable to inhibit platelet aggregation induced by arachidonic acid in whole blood [20]. Therefore, it was important to study the effect of NSC23766 on platelet activation in blood and PRP.

NSC23766 $(300 \mu \mathrm{M})$ was able to almost completely block ( 95\% inhibition) platelet aggregation induced by TRAP $(5 \mu \mathrm{M})$ in whole blood similar to thrombin$(0.5 \mathrm{U} / \mathrm{ml})$ induced aggregation of washed platelets [13]. Thrombin activates PAR-1 and PAR-4 receptors, whereas TRAP only the PAR-1 receptor. A previous study has shown rapid activation and redistribution of Rac from the platelet interior to the cell periphery after TRAP-induced activation of platelets indicating that PAR-1 activation stimulates Rac [21]. It is not known whether PAR-4 activation also signals to Rac1 activation.

NSC23766 was also able to block human platelet aggregation in blood induced by other platelet agonists, such as fibrillar collagen, atherosclerotic plaque, and ADP, suggesting a central role of Rac1 signaling downstream of GPVI (collagen and atherosclerotic plaque) [5] and ADP receptors. These results are in part supported by studies of Rac1-deficient mice platelets, which showed inhibition of GPVI-dependent platelet activation $[9,12,14]$. However, in sharp contrast to two of these studies which reported only inhibition of collagenstimulated, but not thrombin-induced platelet activation in Rac1-deficient mice [9,14], our study shows that Rac1 plays a role in platelet activation induced by all stimuli studied. Concerning the mechanism of ADP-receptor signaling to Rac in human platelets, it was shown that externally added ADP activates Rac through the activation of the $P 2 Y_{1}$ receptor $/ G_{q}$ pathway. However, when ADP was secreted from TRAP-stimulated platelets activation of the $\mathrm{P} 2 \mathrm{Y}_{12}$ receptor $/ \mathrm{G}_{\mathrm{i}}$ pathway played a central role [22].

Dose-response curves showed that NSC23766 inhibited human platelet aggregation in blood and PRP stimulated by all these agonists with a similar $\mathrm{IC}_{50}$ ranging between 50 to $70 \mu \mathrm{M}$. NSC23766 acts by disrupting the interaction of Rac1 with TrioN or Tiam1 Rac-GEFs, and it has been shown to inhibit in vitro both Rac1-TrioN binding and GEF activity of TrioN in a dose dependent manner, achieving $50 \%$ inhibition at $50 \mu \mathrm{M}$ [15]. It is puzzling that the $\mathrm{IC}_{50}$ of NSC23766 for inhibition of stimulus-induced platelet aggregation in blood was found to be in the same range as the $\mathrm{IC}_{50}$ of NSC23766 in the in vitro reconstitution system consisting only of the two proteins Rac1 and TrioN. We expected that much higher concentrations of NSC23766 would be needed to inhibit Rac1 in platelets in blood considering the possible binding of the drug to plasma proteins and other blood cells and its crossing of the cell membrane before reaching its target Rac1 in the platelet interior. Platelet proteome data do not indicate the expression of TrioN or Tiam1 in human platelet (http://plateletweb.bioapps. biozentrum.uni-wuerzburg.de). One possible reason that $\mu \mathrm{M}$ concentrations of NSC23766 were effective in inhibiting Rac1 in platelets in blood is that other Rac1-GEFs might be present in human platelets which have a lower affinity to Rac1 than TrioN or Tiam 1 and are thus displaced by lower (nM) drug concentrations in vitro.

Experiments using RGDS to block the integrin $\alpha_{\mathrm{IIb}} \beta_{3}$ showed that NSC23766 inhibited stimulus-induced secretion of dense granule as well as alpha granule contents in blood and PRP. These results indicate that NSC23766

Table 2 Effect of NSC23766 and aspirin on P-selectin expression of PRP stimulated by ADP and collagen

\begin{tabular}{lcccc}
\hline Agonist & \multicolumn{3}{c}{$\begin{array}{c}\text { P-selectin expression } \\
\text { (\% positive cells) }\end{array}$} \\
\hline & \multicolumn{3}{c}{ PRP } & \multicolumn{2}{c}{ Aspirin-PRP } \\
\cline { 2 - 5 } & Control & Stimulated & Control & Stimulated \\
\cline { 2 - 5 } ADP $(5 \mu \mathrm{M})$ & $1.4 \pm 0.7$ & $6 \pm 2.8$ & $1 \pm 0.5$ & $5.4 \pm 2.6$ \\
ADP+NSC23766 $(300 \mu \mathrm{M})$ & $1.2 \pm 1$ & $1.8 \pm 1.3$ & $0.9 \pm 0.4$ & $2.1 \pm 1.5$ \\
Collagen $(5 \mu \mathrm{g} / \mathrm{ml})$ & $3.3 \pm 3.1$ & $42.4 \pm 16.9$ & $2 \pm 1.3$ & $6 \pm 3.6$ \\
Collagen+NSC23766 $(300 \mu \mathrm{M})$ & $1.8 \pm 1.3$ & $3.1 \pm 2.7$ & $2 \pm 1.5$ & $2 \pm 1.8$ \\
\hline
\end{tabular}

PRP or aspirin-pretreated PRP was incubated with NSC23766 (300 $\mu \mathrm{M})$ or solvent (water) in the presence of 1 mM RGDS for 5 min whilst stirring at $37^{\circ} \mathrm{C}$ in the lumi-aggregometer before stimulation with ADP or collagen. P-selectin expression was measured by flow cytometry. Values are mean \pm SD, $n=4$. 


\section{(A)}

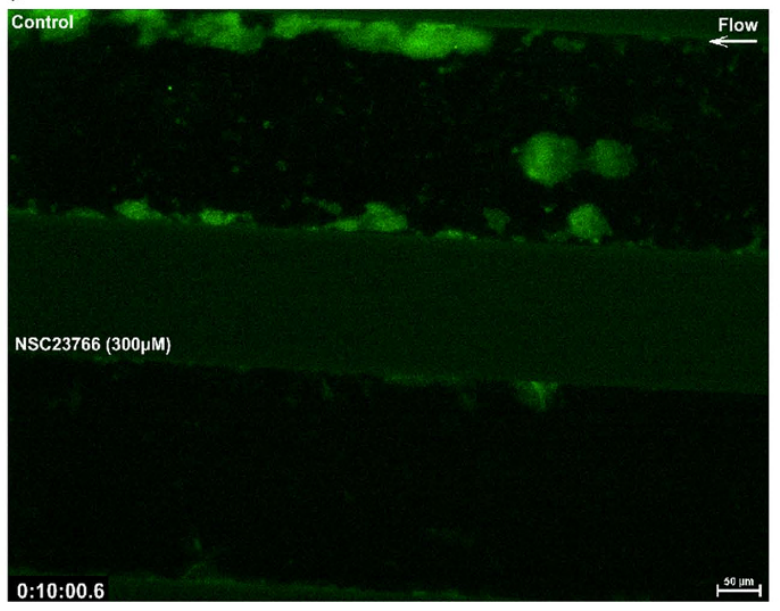

(B)

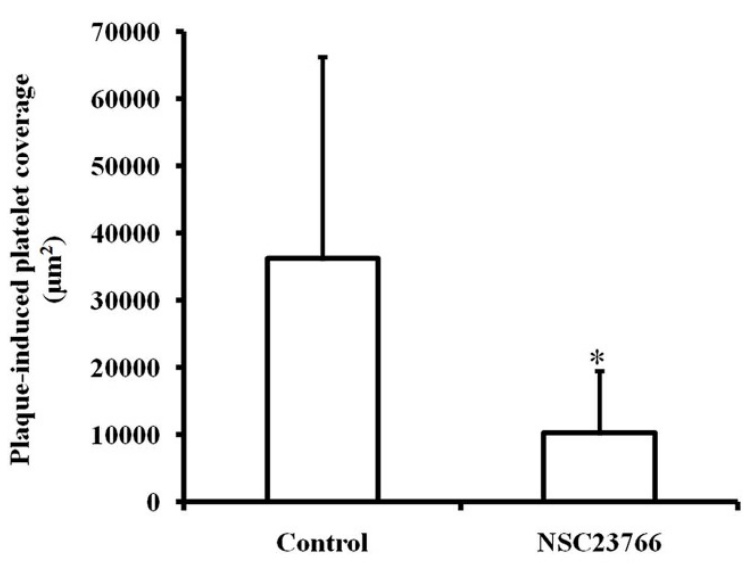

Figure 4 Effect of NSC23766 on atherosclerotic plaque-induced platelet thrombus formation under arterial flow conditions. Hirudinanticoagulated blood pre-incubated with $\mathrm{H}_{2} \mathrm{O}$ or with NSC23766 (300 $\left.\mu \mathrm{M}\right)$ for 5 min was perfused over plaque-coated surfaces for 10 min at $37^{\circ}$ $\mathrm{C}$ at a shear rate of $1500 \mathrm{~s}^{-1}$. (A) representative flow images of control (upper channel) and NSC23766 treated blood (lower channel) 10 min after start of the flow; Platelets are visualized by mepacrine fluorescence; (B) bar diagram (values are mean \pm SD; $n=5$ ). ${ }^{*} p<0.002$.

also primarily inhibits platelet secretion and subsequently platelet aggregation in blood and PRP confirming previous studies in thrombin-stimulated washed platelet suspensions [12,13]. NSC23766 (300 $\mu \mathrm{M})$ completely inhibited platelet P-selectin expression stimulated by collagen and TRAP in blood, but under the same experimental conditions (stirring, presence of RGDS), it did not inhibit completely ATP-secretion (inhibition of 73\% after TRAP stimulation and of $85 \%$ after collagen stimulation). We reasoned that NSC23766 might be so effective in inhibiting collagen- and TRAP-induced platelet aggregation and platelet $\mathrm{P}$-selectin expression in blood because it might inhibit the action of the residual secreted ADP on platelets. Indeed, NSC23766 inhibited ADP-induced aggregation by $70 \%$ and $75 \%$ in blood and PRP, respectively and completely in P-selectin expression.

Another important observation of our study concerns the role of integrin $\alpha_{\mathrm{IIb}} \beta_{3}$ outside-in signaling in the regulation of ATP-secretion in stirred activated blood. RGDS reduced ATP-secretion of stirred blood stimulated with collagen $(0.5 \mu \mathrm{g} / \mathrm{ml})$ and TRAP $(5 \mu \mathrm{M})$ by $63 \%$ and $26 \%$, respectively, indicating that integrin $\alpha_{\text {IIb }} \beta_{3}$ signaling stimulated by platelet-to-platelet contact plays a role that is more important in collagen- than in TRAP-induced dense granule secretion of platelets in blood. These results are in line with a previous study of mice PRP showing the important role of the integrin $\alpha_{\text {IIb }} \beta_{3}$ in mediating secretion after stimulation with low level $(2.5 \mu \mathrm{g} / \mathrm{ml})$ collagen [23].

Aspirin, which reduced P-selectin expression of collagen-stimulated hirudin-anticoagulated PRP by $90 \%$, was ineffective in inhibiting P-selectin expression when hirudin PRP was stimulated with ADP, confirming a previous study in citrated PRP [24]. Thus, aspirin fails to inhibit $\alpha$-granule secretion after ADP stimulation of platelets independent of the anticoagulant used. The findings are in contrast to the results of dense granule secretion in citrated PRP, where aspirin is well known to inhibit dense granule secretion and the secondary wave of platelet aggregation after ADP stimulation [25]. Interestingly, we found that NSC23766 was equally effective in aspirin- and non-aspirin pretreated platelets in reducing $\mathrm{P}$-selectin expression as well as platelet aggregation stimulated by ADP. Two conclusions can be drawn from these results: (1) NSC23766 is much more effective than aspirin in inhibiting the effect of ADP on platelets in blood and (2) NSC23766 inhibits $\alpha$-granule secretion and platelet aggregation stimulated by ADP independent of platelet prostaglandin-endoperoxide and thromboxane formation.

\section{Conclusion}

Our data clearly demonstrate the central role of Rac1 in secretion and subsequent platelet aggregation in blood upon activation by a wide array of platelet stimuli including atherosclerotic plaque. Rac1 inhibition by NSC23766 prevented platelet secretion from both $\alpha$-granules and dense granules. We suggest that by inhibiting specifically platelet secretion, the pharmacological targeting of Rac1 could be an interesting approach in the development of future antiplatelet drugs. 


\section{Additional material}

Additional file 1: Figure S1. Effect of NSC23766 on ATP-secretion and aggregation of PRP stimulated with collagen. PRP was preincubated with or without $300 \mu \mathrm{M}$ NSC23766 (for $5 \mathrm{~min}$ ), with or without 1 mM RGDS (for 2 min; added 3 min after NSC23766 or $\mathrm{H}_{2} \mathrm{O}$ ) whilst stirring at $37^{\circ} \mathrm{C}$ before stimulation with collagen $(1.25 \mu \mathrm{g} / \mathrm{ml})$. (A) Top, tracings of light transmission and ATP-secretion of PRP stimulated by collagen with or without NSC23766. Bottom, tracings of light transmission and ATP-secretion of PRP stimulated by collagen with or without NSC23766 in the presence of RGDS. (B) Dose-response curve of NSC23766 on platelet aggregation and ATP-secretion induced by collagen $(1.25 \mu \mathrm{g} / \mathrm{ml})$. Values are mean $\pm \mathrm{SD}(n=3)$.

Additional file 2: Figure S2. Effect of NSC23766 on ATP-secretion and aggregation of PRP stimulated with plaque. PRP was preincubated with or without $300 \mu \mathrm{M}$ NSC23766 (for $5 \mathrm{~min}$ ), with or without 1 mM RGDS (for 2 min; added 3 min after NSC23766 or $\mathrm{H}_{2} \mathrm{O}$ ) whilst stirring at $37^{\circ} \mathrm{C}$ before stimulation with plaque $(0.62 \mathrm{mg} / \mathrm{ml})$. (A) Top, tracings of light transmission and ATP-secretion of PRP stimulated by plaque with or without NSC23766. Bottom, tracings of light transmission and ATP-secretion of PRP stimulated by plaque with or without NSC23766 in the presence of RGDS. (B) Dose-response curve of NSC23766 on platelet aggregation and ATP-secretion induced by plaque $(0.62 \mathrm{mg} / \mathrm{ml})$. Values are mean $\pm \mathrm{SD}(n=3)$.

Additional file 3: Movie S1. Effect of NSC23766 on human plaqueinduced platelet thrombus formation under arterial flow conditions. Hirudin-anticoagulated blood was incubated with mepacrine to visualize platelets by fluorescence. Blood was perfused (direction right to left) over atherosclerotic plaque-coated microfluidic chambers and observed for 10 min. Upper channel, control; lower channel, blood pre-treated with 300 IM NSC23766. In the upper channel, rapid platelet adhesion and aggregate formation (green fluorescence) occurred, mainly at the edges of the channel, where also the majority of plaque material is present (as seen by phase contrast microscopy before start of the flow experiments). NSC23766 reduced platelet adhesion and aggregate formation. The video is in. mov format and can be viewed using Quick time player on different PCs with Windows XP or Vista.

\section{Acknowledgements}

We thank Kathrin von Oheimb for her technical assistance in this study. The study was supported by grants from the Deutsche Forschungsgemeinschaft (DFG Si 274/11), the August-Lenz-Stiftung, the University of Munich and the Bayern University ("BayEFG"; to A.L.K.). The results are part of the doctoral thesis of S.D. at the University of Munich.

\section{Author details}

'Institute for Prevention of Cardiovascular Diseases, University of Munich, Munich, Germany. ${ }^{2}$ Department of Vascular Surgery, Clinic Schwabing, Munich, Germany. ${ }^{3}$ Max-Planck Institute of Biochemistry, Martinsried, Germany.

\section{Authors' contributions}

SD designed and performed the experiments, collected the results and analyzed the data. DP contributed by designing some of the experiments and interpreting the results. AKL participated in helping to perform the flow experiments. RB provided human plaque material. WS planned the study, assisted in designing the experiments, discussed and interpreted the results throughout the study, and wrote together with SD and DP the paper. All the authors have read and approved the final manuscript.

\section{Competing interests}

The authors declare that they have no competing interests.

Received: 17 September 2010 Accepted: 6 December 2010 Published: 6 December 2010

\section{References}

1. Fernandez-Ortiz A, Badimon JJ, Falk E, Fuster V, Meyer B, Mailhac A, Weng D, Shah PK, Badimon L: Characterization of the relative thrombogenicity of atherosclerotic plaque components: implications for consequences of plaque rupture. J Am Coll Cardiol 1994, 23:1562-1569.

2. Vanzanten GH, Degraaf S, Slootweg PJ, Heijnen HFG, Connolly TM, Degroot PG, Sixma JJ: Increased Platelet Deposition on Atherosclerotic Coronary-Arteries. Journal of Clinical Investigation 1994, 93:615-632.

3. Siess W, Zangl KJ, Essler M, Bauer M, Brandl R, Corrinth C, Bittman R, Tigyi G, Aepfelbacher M: Lysophosphatidic acid mediates the rapid activation of platelets and endothelial cells by mildly oxidized low density lipoprotein and accumulates in human atherosclerotic lesions. Proceedings of the National Academy of Sciences of the United States of America 1999, 96:6931-6936.

4. Rother E, Brandl R, Baker DL, Goyal P, Gebhard H, Tigyi G, Siess W: Subtypeselective antagonists of lysophosphatidic Acid receptors inhibit platelet activation triggered by the lipid core of atherosclerotic plaques. Circulation 2003, 108:741-747.

5. Penz S, Reininger AJ, Brandl R, Goyal P, Rabie T, Bernlochner I, Rother E, Goetz C, Engelmann B, Smethurst PA, et al: Human atheromatous plaques stimulate thrombus formation by activating platelet glycoprotein VI. FASEB J 2005, 19:898-909.

6. Reininger AJ, Bernlochner I, Penz SM, Ravanat C, Smethurst P, Farndale RW, Gachet C, Brandl R, Siess W: A 2Step Mechanism of Arterial Thrombus Formation Induced by Human Atherosclerotic Plaques. Journal of the American College of Cardiology 2010, 55:1147-1158.

7. Bauer M, Retzer M, Wilde Jl, Maschberger P, Essler M, Aepfelbacher M, Watson SP, Siess W: Dichotomous regulation of myosin phosphorylation and shape change by Rho-kinase and calcium in intact human platelets. Blood 1999, 94:1665-1672.

8. Klages B, Brandt U, Simon MI, Schultz G, Offermanns S: Activation of G12/ G13 results in shape change and Rho/Rho-kinase-mediated myosin light chain phosphorylation in mouse platelets. J Cell Biol 1999, 144:745-754.

9. McCarty OJ, Larson MK, Auger JM, Kalia N, Atkinson BT, Pearce AC, Ruf S, Henderson RB, Tybulewicz VL, Machesky LM, Watson SP: Rac1 is essential for platelet lamellipodia formation and aggregate stability under flow. $J$ Biol Chem 2005, 280:39474-39484.

10. Soulet C, Gendreau S, Missy K, Benard V, Plantavid M, Payrastre B: Characterisation of Rac activation in thrombin- and collagen-stimulated human blood platelets. FEBS Lett 2001, 507:253-258.

11. Gratacap MP, Payrastre B, Nieswandt B, Offermanns S: Differential regulation of Rho and Rac through heterotrimeric G-proteins and cyclic nucleotides. J Biol Chem 2001, 276:47906-47913.

12. Akbar H, Kim J, Funk K, Cancelas JA, Shang X, Chen L, Johnson JF, Williams DA, Zheng Y: Genetic and pharmacologic evidence that Rac1 GTPase is involved in regulation of platelet secretion and aggregation. J Thromb Haemost 2007, 5:1747-1755.

13. Pandey D, Goyal P, Dwivedi S, Siess W: Unraveling a novel Rac1-mediated signaling pathway that regulates cofilin dephosphorylation and secretion in thrombin-stimulated platelets. Blood 2009, 114:415-424.

14. Pleines I, Elvers M, Strehl A, Pozgajova M, Varga-Szabo D, May F, ChrostekGrashoff A, Brakebusch C, Nieswandt B: Rac1 is essential for phospholipase C-gamma2 activation in platelets. Pflugers Arch 2009, 457:1173-1185.

15. Gao Y, Dickerson JB, Guo F, Zheng J, Zheng Y: Rational design and characterization of a Rac GTPase-specific small molecule inhibitor. Proc Natl Acad Sci USA 2004, 101:7618-7623.

16. Brandl R, Richter T, Haug K, Wilhelm MG, Maurer PC, Nathrath W: Topographic analysis of proliferative activity in carotid endarterectomy specimens by immunocytochemical detection of the cell cycle-related antigen Ki-67. Circulation 1997, 96:3360-3368.

17. Penz SM, Reininger AJ, Toth O, Deckmyn H, Brandl R, Siess W: Glycoprotein Ibalpha inhibition and ADP receptor antagonists, but not aspirin, reduce platelet thrombus formation in flowing blood exposed to atherosclerotic plaques. Thromb Haemost 2007, 97:435-443.

18. Toth O, Calatzis A, Penz S, Losonczy H, Siess W: Multiple electrode aggregometry: a new device to measure platelet aggregation in whole blood. Thromb Haemost 2006, 96:781-788.

19. Ingerman CM, Smith JB, Silver MJ: Direct measurement of platelet secretion in whole blood. Thromb Res 1979, 16:335-344. 
20. Saniabadi AR, Lowe GD, Belch JJ, Barbenel JC, Forbes CD: Effect of prostacyclin (epoprostenol) on the aggregation of human platelets in whole blood in vitro. Haemostasis 1984, 14:487-494.

21. Azim AC, Barkalow K, Chou J, Hartwig JH: Activation of the small GTPases, rac and cdc42, after ligation of the platelet PAR-1 receptor. Blood 2000, 95:959-964.

22. Soulet C, Hechler B, Gratacap MP, Plantavid M, Offermanns S, Gachet C, Payrastre B: A differential role of the platelet ADP receptors $\mathrm{P} 2 \mathrm{Y} 1$ and P2Y12 in Rac activation. J Thromb Haemost 2005, 3:2296-2306.

23. Cho MJ, Liu J, Pestina TI, Steward SA, Thomas DW, Coffman TM, Wang D, Jackson CW, Gartner TK: The roles of alpha Ilb beta 3-mediated outside-in signal transduction, thromboxane $\mathrm{A} 2$, and adenosine diphosphate in collagen-induced platelet aggregation. Blood 2003, 101:26462651.

24. Rinder CS, Student LA, Bonan JL, Rinder HM, Smith BR: Aspirin does not inhibit adenosine diphosphate-induced platelet alpha-granule release. Blood 1993, 82:505-512.

25. Siess W: Molecular mechanisms of platelet activation. Physiol Rev 1989, 69:58-178.

doi:10.1186/1479-5876-8-128

Cite this article as: Dwivedi et al:: Rac1-mediated signaling plays a central role in secretion-dependent platelet aggregation in human blood stimulated by atherosclerotic plaque. Journal of Translational Medicine 2010 8:128.

\section{Submit your next manuscript to BioMed Central} and take full advantage of:

- Convenient online submission

- Thorough peer review

- No space constraints or color figure charges

- Immediate publication on acceptance

- Inclusion in PubMed, CAS, Scopus and Google Scholar

- Research which is freely available for redistribution

Submit your manuscript at www.biomedcentral.com/submit 